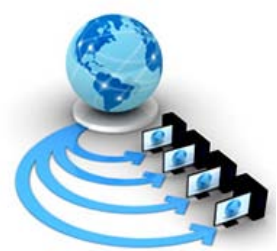

Volume 11, No. 2, March-April 2020

ISSN No. 0976-5697

International Journal of Advanced Research in Computer Science

RESEARCH PAPER

Available Online at www.ijarcs.info

\title{
SURVEY: MATHEMATICAL MODELS FOR THE REGULATION MECHANISM OF GLUCOSE BY PANCREAS'S HORMONES IN THE HUMAN BODY
}

\author{
Baida'a Lala’a, Ghaleb Al-Gaphariand Nabeel Alsohybe \\ Faculty of Computer and Information Technology, Sana'a University, Sana'a, Yemen
}

\begin{abstract}
Optimization algorithms are techniques for solving optimization problems in different areas. Anyone cannot obtain an optimal, precise, and complete solution as those existed in the universe, whether nature behaviour in living creatures, cosmic systems, or at the level of the mechanism of systems in the human body. One of these systems is the system of regulation blood glucose levels in the human body. This system maintains blood glucose levels in a stable condition without increase or decrease. There are many medical, biochemistry, bionic engineering, and physiology researches that have studied the mechanism of regulation of glucose in the human body and the crystallization of the mechanism in the form of mathematical models, which greatly facilitate understanding the mechanism of pancreas hormones and regulation mechanism. However, there is a lack in researches that demonstrate the sequential integrative processes between three main sub-systems and the parallel integrative processes between components of theses sub-systems for managing blood glucose level. Therefore, this research aims to expand on the field of regulation mechanisms of blood glucose. It covers the mechanism with thirteen models that mathematically clarify the mechanism of components of the blood glucose levels regulation in the human body to understand the divine system in the process of the regulation, which may be inspired to create a general method that used to solve optimization problems.
\end{abstract}

Keywords: Mathematical models, Glucose homeostasis, pancreas hormones

\section{INTRODUCTION}

Glucose homeostasis is one of the most critical phenomena in the human body. Glucose can originate exogenously from ingestion of food, and, also, endogenously from the liver by glycogenolysis (re-converting stored glycogen). The absorption of glucose in the cells determines the actual concentration of blood glucose. Integrated hormonal and enzymatic processes control all of this. The system comprises of many complicated sub-processes; whose erroneous activity usually leads to common diabetic diseases [1]. The human body system consists of various organs. Those organs have their specific functions and play their roles in maintaining relevant biological activities in the body. Each organ needs a stable and adequate glucose supply from the blood to carry through its function. It is, therefore, important to keep the optimal blood glucose level [2]. The two main organs involved in the maintenance of glucose homeostasis are the pancreas and the liver. The role of the pancreas is to release the two most important hormones that control glucose homeostasis: insulin and glucagon. They are produced in pancreatic- $\beta$ cells andpancreatic- $\alpha$-cells, respectively[3], [4], [5]. When the blood glucose level is high, $\beta$ cells secrete insulin to help cells in the process of glucose absorption. Whereas, $\alpha$-cells secret glucagon when blood glucose levels fall below normal. It acts as an antagonist of insulin by causing hepatic glucose output to rise[3], [5], [6]. Whereas, the role of the liver acts as a storage organ of excess blood glucose. When blood glucose levels are high, it takes up glucose and converts it into glycogen. When glucose levels are low, it releases glucose by either glycogenolysis or synthesizing new glucose (gluconeogenesis)[7]. Figure 1 illustrates the mechanism of glucose homeostasis
I. INTEGRATION BETWEEN INSULIN AND GLUCAGON TO REGULATE BLOOD GLUCOSE LEVEL

Figure 1 shows the process of glucose absorption that passes through several stages. It further illustrates that several organs intervene in glucose homeostasis. It is preferable to break down the mechanism into partial stages (sub-models) to understand the mechanism of blood glucose regulation in the human body.

This section explains complementary work between insulin and glucagon for managing the process of blood glucose regulation. It consists of three sub-headings: a) The glucose sub-model, b) The insulin sub-model, and c) The glucagon sub-model.

A. The glucose sub-model

Glucose $\left(\mathrm{C}_{6} \mathrm{H}_{12} \mathrm{O}_{6}\right)$ is a monosaccharide used as the main source of energy in the body[8]. Plasma glucose can originate exogenously from the ingestion of food and also endogenously from the liver by glycogenolysis[9]. This plasma passes through the cells, pancreas, and other organs in the body[8]. Glucose enters the cell by facilitated diffusion mechanisms, which represent an example of regulated mass exchange across the cell membrane. Specialized families of membrane proteins called GLUT (i.e., GLUcose Transporters [10]), observed in a large variety of cell types[10], actively operate the removal of free glucose from the interstitial spaces and transport it inside the cytoplasm, with distinct affinities and maximal transport rates [5].The absorption of glucose in the cells determines the actual concentration of blood glucose [1] The pancreas is one of the most important organs in glucose homeostasis. It Continuously monitors blood glucose level that occurs when plasma glucose passes continuously through the pancreas's glucose transporter, the pancreas, in turn, secrete the appropriate hormone (insulin or glucagon) to regulate blood glucose level. 


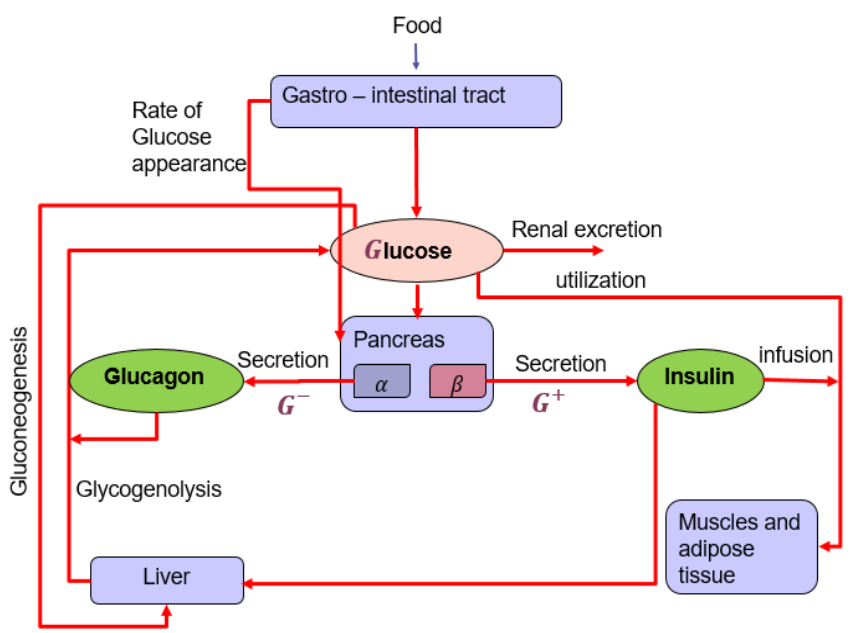

Figure 1. Mechanism of Regulation of Glucose level in the human body: Plasma Glucose enters into Pancreas organs, which can determine the rate of blood glucose. At high glucose concentration, this stimulates pancreatic $\beta$-cells to secrete insulin hormone. After plasma insulin is distributed to interstitial fluid, it activates glucose uptake by the target cells (as muscles) by bindinginsulin to cell membrane receptors, which allow it to enter the glucose by target cell's transporter using complicated subprocesses. Whereas, atlow glucose concentration, pancreatic $\alpha$ cells secrete glucagon hormone that releases glucose by either glycogenolysis (re-converting stored glycogen from the liver) or synthesizing new glucose (gluconeogenesis). The excess proportion of the body is being removed from the body (renal excretion).

\section{B. The insulin sub-model Insulin}

Insulin is a hormone secreted by the pancreas within the $\beta$-cells of the islets of Langerhans.[3],[4],[5] . Insulin has the most important role in maintaining glucose homeostasis. It enables glucose uptake by muscle and adipose tissue cells. It alsoregulates the storage and releases of glucose in the liver and promotes fat synthesis and storage [5]. The pancreas secretes plasma insulin into the portal vein, where it first passes through the liver and subsequently enters systemic circulation [8]. Glucose uptake is activated once plasma insulin is distributed to interstitial fluid, where insulin bind to cellmembrane receptors[8].

\section{Glucose-dependent regulation of Insulin secretion}

Through previous studies, glucose-dependent regulation of Insulin secretion can be summarized into the following steps (Figure 2):

1. Glucose enters into pancreatic $\beta$-cells and is metabolized through the glycolytic pathway and subsequently in mitochondria[11].

2. The resultant increase in ATP production leads to closure of the ATP-sensitive potassium $\left(\mathrm{K}_{\mathrm{ATP}}\right)$ channel leading to membrane depolarization[11]( depolarizing the membrane potential to a range where the inactivation of voltage-dependent channels takes place. This results in the inhibition of electrical activity, $\mathrm{Ca}^{2+}$ influx, and glucagon secretion[12]).

3. This causes $\mathrm{Ca}^{2+}$ entry through the voltage-dependent $\mathrm{Ca}^{2+}$ channel and elevation of cytoplasmic $\mathrm{Ca}^{2+}$ concentration $\left(\left[\mathrm{Ca}^{2+} \mathrm{c}\right)\right.$, which initiates exocytosis of insulin granules [11].

4. The main feature of insulin secretion is its biphasic secretion pattern[9].
a.This pattern was earlier described by a mathematical model developed by [14]. The model describes insulin as stored packets inside the $\beta$-cells, and each insulin packet has a specific threshold-level to glucose concentration. When the glucose concentration increases, a specific number of insulin packets are secreted into the blood.

b.Recently, the movement of insulin granules inside $\beta$ cells, and the mechanism of exocytosis have been revealed by total internal reflection fluorescence microscopy (TIRFM) [15]-[17].

c.The insulin granules can be further divided into different insulin pools according to the different movement patterns and relative locations [17].

d. Readily releasable pools, composed of insulin granules adjacent to the plasma membranes of $\beta$-cells, exist in a fully releasable state and are associated with the fast first phase of insulin secretion.

e. These pools provide quick response of insulin secretion to a sudden glucose increase. In the cell plasma of the $\beta$-cells, insulin granules denoted reserve pools secrete insulin granules for maintaining the baseline insulin level and producing the second-phase insulin secretion through the nonstandard secretion pathway and provide supplemental insulin granules to the readily releasable pools [17]. Several other kinetic models have been proposed to describe the biphasic secretion pattern and provided agreement with data from different experimental approaches[9],[18]-[21].

5. Gupta et al. proposed an insulin kinetic model to analyze the insulin kinetics of $\beta$-cells, post hepatic insulin delivery, and insulin elimination [22]. The model has detailed descriptions of the insulin pools inside the $\beta$-cells and of how glucose affects insulin production and secretion.

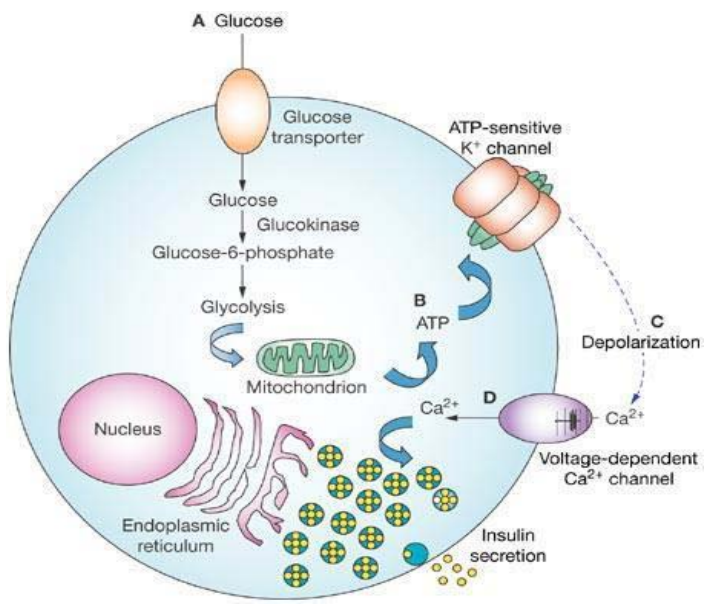

Figure 2: schema of the mechanism of insulin secretion [23]

\section{- $\quad$ Glucose - Insulin mechanism}

Glucose uptake is activated once plasma insulin is distributed to interstitial fluid, where it binds to cellmembrane receptors.

Figure 3 shows steps of entering glucose to the target cell, which is summarized as a following:

1. Cells can communicate with each other by sending and receiving signals, which include hormonal signals from distant endocrine cells, paracrine signals from neighboring cells, or autocrine sensing of signals emitted from the same cell. Cell surface or transmembrane receptors on the plasma 
membrane provide cells with the means of sensing different ligands in their environment with relevant signaling cascades, without specific uptake of the respective ligands. [24]

2. Insulin binds to the receptor of the cell[11]

3. The binding process leads to stimulate the signal transduction cascade to stimulate the cell to the Exocytosis process.

4. Exocytosis (moving target cell 's transporter to the cell membrane surface to allow the glucose to enter the cell)

5. The target cell 's transporter enters glucose from the interstitial spaces and transports it inside the cytoplasm with distinct affinities and maximal transport rates [5].

When insulin secretion phases are faded. At that time, the purpose of insulin secretion has been achieved which is to access to desired balancing by reducing blood glucose level.

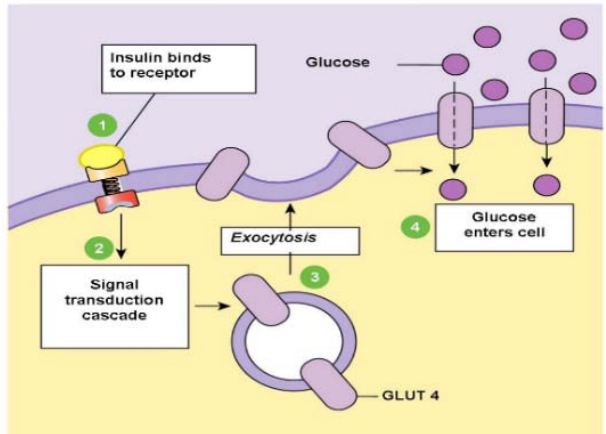

Figure 3: Steps of Glucose entering to target cell [25].

\section{Glucagon sub-model \\ - Glucagon}

Glucagon is a hormone that secreted by pancreatic $\alpha$-cells. Under normal circumstances, the elevation of glucose has opposite effects on the secretion of glucagon from the alpha-cells. When blood glucose levels fall below normal, particularly during fasting and exercise. It also acts as an antagonist of insulin by causing hepatic glucose output to rise. This is either achieved by glycogen breakdown (Glycogenolysis) or increased gluconeogenesis (storing excess circulating glucose as glycogen in the liver). [7]. If glycogen stores are saturated, glucose is converted into fat and stored in the liver and fat cells in the adipose tissue. These processes can be reversed when energy demand is high. Glucose is rapidly released from glycogen via the glycogenolysis process if glycogen stores are used, once the fat is used via the gluconeogenesis process with amino acids to form glucose [8]. Both glycogenolysis and gluconeogenesis are commonly grouped under and described as endogenous glucose production (EGP)). EGP is tightly regulated in the healthy body to maintain basal (minimum) blood glucose concentration. EGP represents net glucose production by the body, primarily by the liver, and released into the blood. EGP is suppressed when blood glucose concentration is considerably high due to external glucose appearance through meals or to a lesser extent via intravenous bolus. However, low glucose concentrations inverse the process by stimulating glucagon secretion via pancreatic $\alpha$-cells, which activates glycogenolysis and thus rapidly increases glucose concentrations to prevent hypoglycemia. The rate of endogenous glucose production is a function of both stimulus and the availability of substrates. In reality, EGP is modulated by the interaction of many hormones in response to metabolic dysfunctions that cause insulin sensitivity irregularities. As tissue cells fail to respond adequately to insulin, blood glucose concentrations rise. Normally, the liver helps regulate glucose concentrations by reducing glucose production in the presence of insulin. [8]

\section{- Glucose-dependent regulation of Glucagon secretion}

Alpha-cell models are not available to the same extent as $\beta$ cell models[12], [26]. Through previous studies, which is proposed to be since potential action generation in alphacells is dependent on T-type $\mathrm{Ca}^{2+}$ channels and $\mathrm{Na}^{+}$ channels, which inactivate and cause decreased electrical excitability.

Glucose-dependent regulation of Glucagon secretion can be summarized in the following steps:

1. Glucose is incorporated into the $\alpha$-cell by the transporter.

2. At low-glucose concentrations, the moderate activity of $\mathrm{K}_{\mathrm{ATP}}$ channels situates the $\alpha$-cell membrane potential in a range that allows the opening of voltage-dependent $\mathrm{T}$ and $\mathrm{N}$-type $\mathrm{Ca}^{2+}$ channels and voltage-dependent $\mathrm{N}^{+}$ channels[12](Figure 4).

- The opening of A-type $\mathrm{K}^{+}$channels is necessary for action potential repolarization.[12]

3. Most of the $\mathrm{Ca}^{2+}$ current goes through L-type channels in $\alpha$-cells, the $\mathrm{Ca}^{2+}$ required for exocytosis at lowglucose levels is mediated by $\mathrm{N}$-type channels.[12].

- Their blockade inhibits glucagon secretion in this range that allows the opening of voltage-dependent $\mathrm{T}$ - and $\mathrm{N}$-type $\mathrm{Ca}^{2+}$ channels and voltage-dependent $\mathrm{Na}^{+}$channels.[12]. However, Their activation triggers action potentials, $\mathrm{Ca}^{2+}$ influx, and exocytosis of glucagon granules.[12]

4. Glycogenolysis.

5. Subsequently, blood glucose level rises, and through continuous monitoring of glucose level by the pancreas. It makes the right decision by choosing the appropriate hormone to keep the blood glucose level in the normal range.

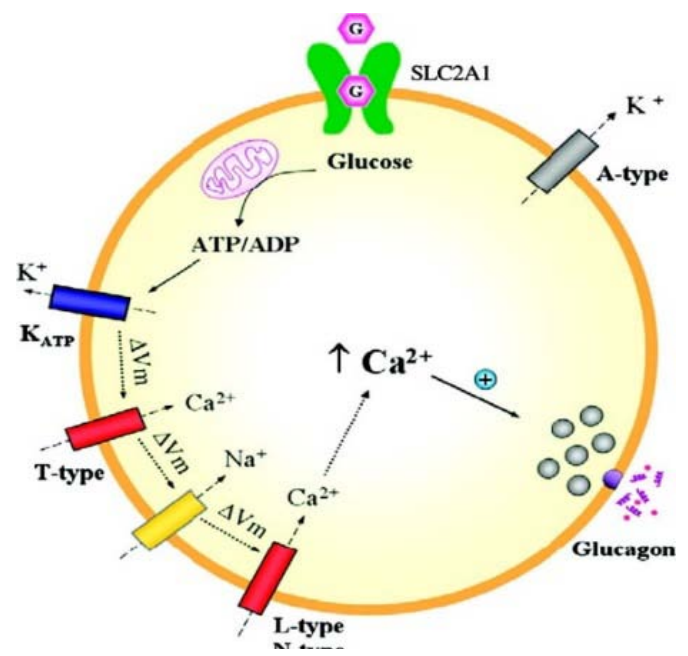

Figure 4:Schematic model for glucose-dependent regulation of glucagon secretion in the mouse a-cell [12] 


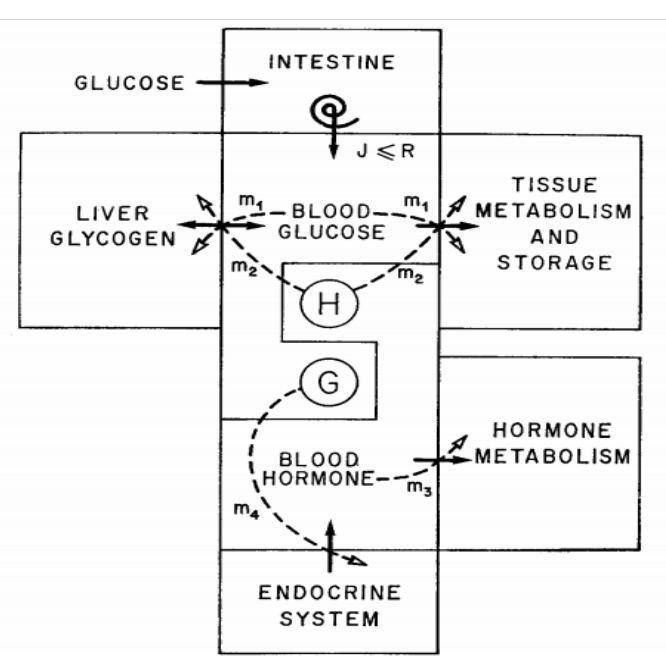

Figure 5: a simplified model of the blood glucose regulatory system using by Ackerman (Ref. [27]).

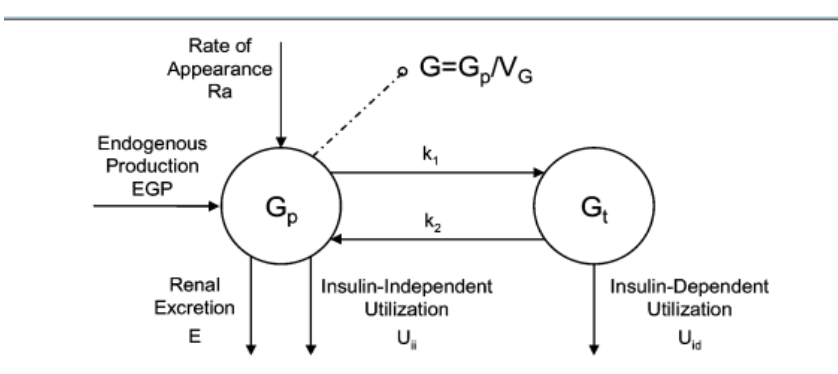

INSULIN

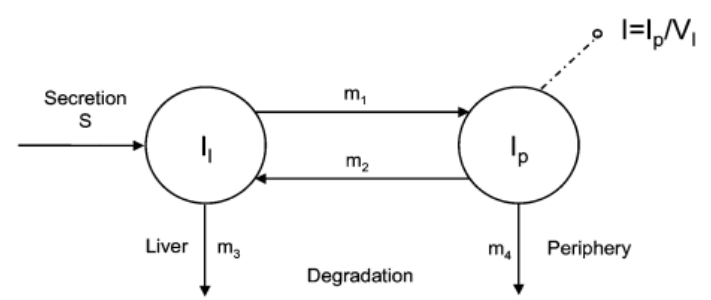

Figure 6: Schema of Glucose and insulin sub-systems in the Dalla Man model (Ref. [28]).

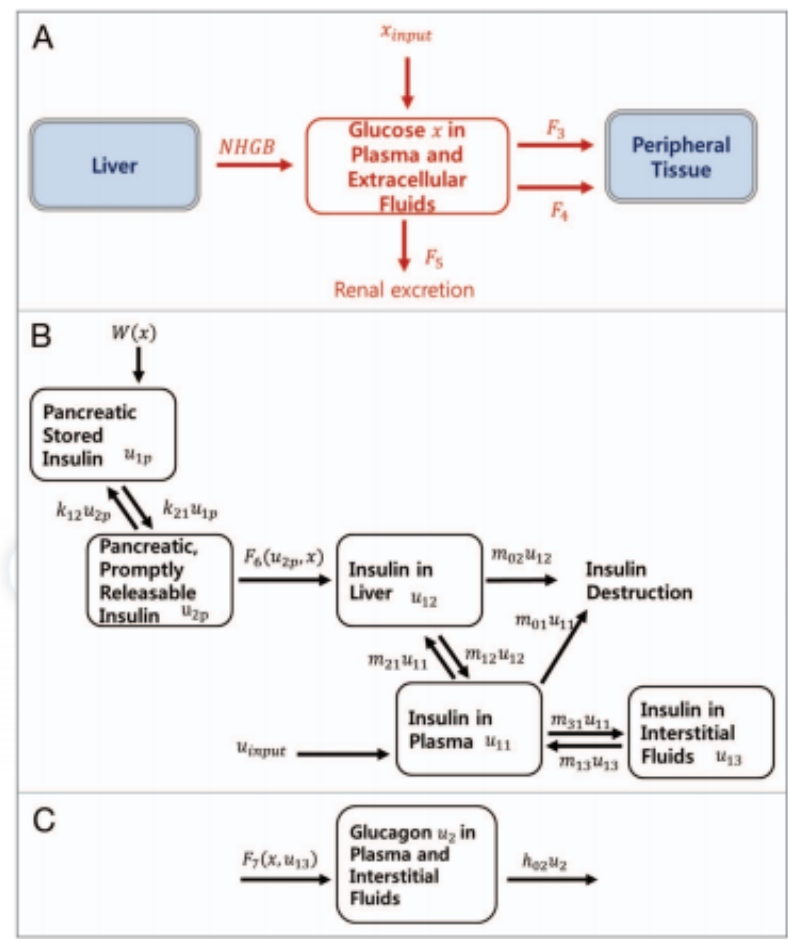

Figure 7: Schematic diagram of the integrated mathematical model consisting of three sub-systems: (A) glucose sub-system, (B) insulin sub-system, and (C) glucagon sub-system. Red and black arrows illustrate the transport of glucose and insulin, respectively (Ref.[2]).

II. MATHEMATical MODEls FOR THE REgulation MECHANISM OF GLUCOSE BY PANCREAS'S HORMONES IN THE HUMAN BODY (TABLE1)

Table 1: Mathematical models for blood glucose levels regulation

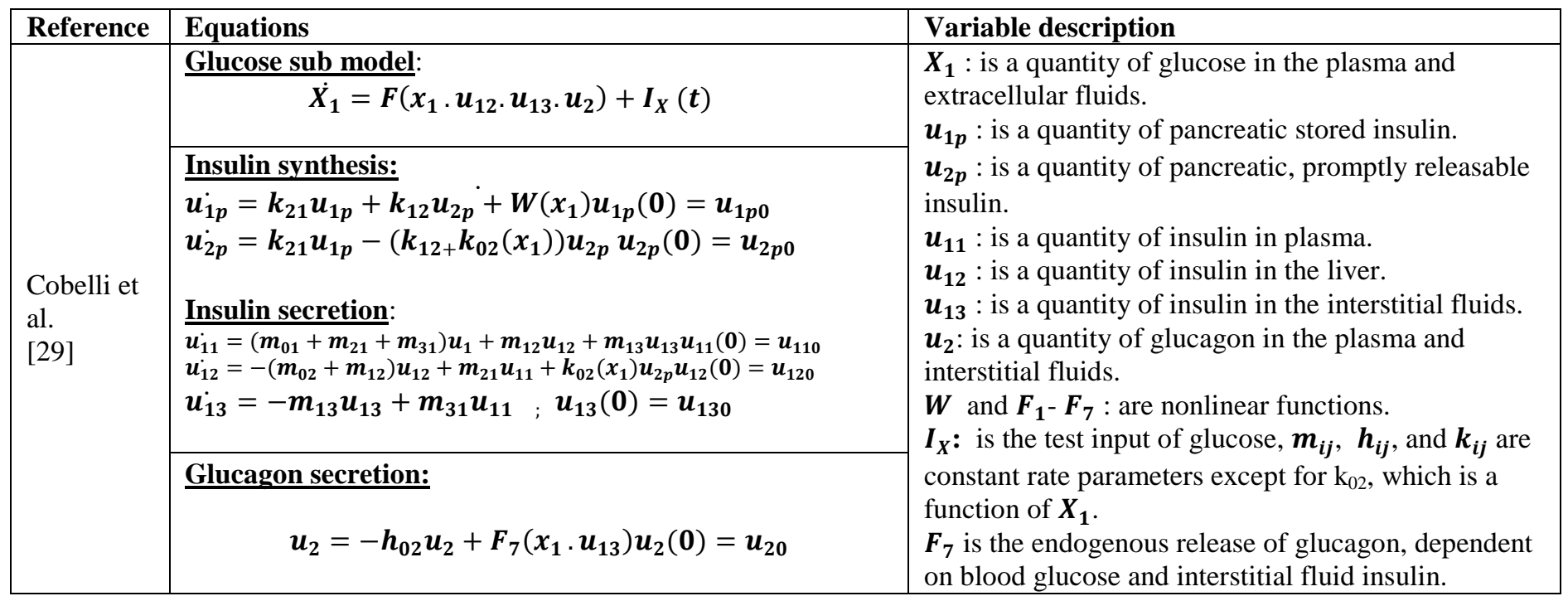




\begin{tabular}{|c|c|c|}
\hline Reference & Equations & Variable description \\
\hline \multirow[b]{2}{*}{$\begin{array}{l}\text { Ackerman } \\
\text { et al. [27] } \\
\text { The model } \\
\text { also used } \\
\text { in [30] }\end{array}$} & Glucose equation: & \multirow{2}{*}{$\begin{array}{l}\boldsymbol{G}: \text { is the glucose concentration. } \\
\boldsymbol{H}: \text { is glucose-regulating hormones. } \\
\boldsymbol{G}_{\mathbf{0}} \text { and } \boldsymbol{H}_{\mathbf{0}}: \text { are the change in the values of G or H, } \\
\text { respectively. } \\
\boldsymbol{m}_{\mathbf{1}}: \text { rate constant for the removal of glucose above } \\
\text { the initial (fasting) level due to its own excess above } \\
\text { the initial level. } \\
\boldsymbol{m}_{2}: \text { rate constant for the removal of glucose above } \\
\text { the initial level due to blood-hormone concentrations } \\
\text { above the initial level. } \\
\boldsymbol{m}_{\mathbf{3}}: \text { rate constant for the removal of hormone above } \\
\text { the initial (fasting) level due to its own excess above } \\
\text { the initial level. } \\
\boldsymbol{m}_{\mathbf{4}}: \text { rate constant for the release of hormone above } \\
\text { the initial level due to blood-glucose concentrations } \\
\text { above the initial level. } \\
\boldsymbol{J}(t) \text { and } \boldsymbol{K}(\boldsymbol{t}): \text { are the rate of infusion of exogenous } \\
\text { glucose and insulin, respectively. Figure } \mathbf{5}\end{array}$} \\
\hline & Hormone equation: & \\
\hline $\begin{array}{l}\text { Minimal } \\
\text { model } \\
(\mathrm{MM}) \\
\text { Bergman } \\
\text { et al. } \\
\text { [31], [32] } \\
\text { Other } \\
\text { research } \\
\text { using MM } \\
\text { [31], [33]- } \\
\text { [36] }\end{array}$ & $\begin{array}{l}\text { The physiological factors that determine the restoration } \\
\text { of plasma glucose after injection: } \\
\text { Glucose restoration rate }=- \text { (glucose effectiveness + remote } \\
\text { insulin) } \mathrm{G} \text { or } \\
\qquad \frac{d g}{d t}=-\left(S_{G}+X(t)\right) G+C \\
\text { The factors that determine the level of insulin in the } \\
\text { interstitial. } \\
\text { increase in remote insulin }=\mathrm{k}_{\mathrm{a}} \text { (plasma insulin) - } \mathrm{k}_{\mathrm{b}} \\
\text { (remote insulin) or } \\
\qquad \frac{d X(t)}{d t}=-\left(k_{a} I(t)-k_{b} X(t)\right)\end{array}$ & $\begin{array}{l}S_{G}: \text { is the effect of glucose itself. } \\
X(t): \text { is the effect of insulin in the interstitial } \\
\text { compartment, which acts synergistically with glucose } \\
\text { to return the glycemia to basal levels. } \\
X(t) \text { is increased by plasma insulin [ } I(t) \text { determined } \\
\text { by } k_{a} \text { ] but decreases by a first-order process } \\
\text { proportional by } k_{b} \text { to interstitial insulin itself } \\
{\left[k_{b} X(t)\right] \text {. }} \\
\text { Parameter C accounts for glucose production at basal } \\
\text { insulin. }\end{array}$ \\
\hline $\begin{array}{l}\text { K. } \\
\text { Zarkogian } \\
\text { ni, et al. } \\
\text { [37] }\end{array}$ & 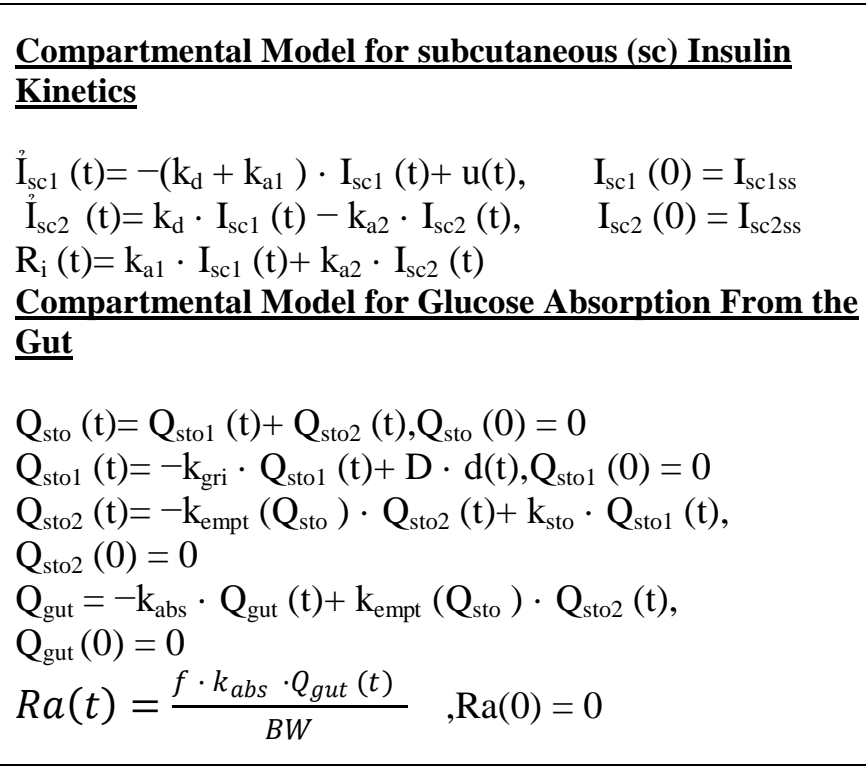 & 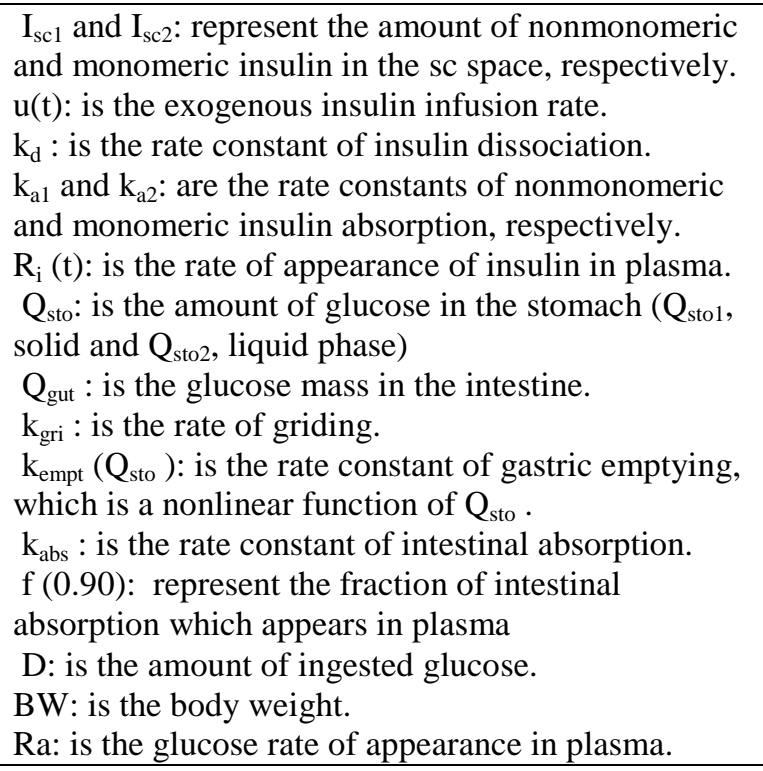 \\
\hline $\begin{array}{l}\text { Cobelli et } \\
\text { al. [38] }\end{array}$ & $\begin{array}{l}\text { Static Mode: } \\
\qquad \begin{array}{l}I R(t)=R I\left[\frac{y_{i}(t)-B I}{Q I}+1\right]^{2} \cdot \frac{y_{i}(t)-B I}{Q I}+1>0 \\
\operatorname{IR}(\mathrm{t})=0 \quad . \frac{y_{1}(t)-B I}{Q I}+1 \leq 0\end{array}\end{array}$ & $\begin{array}{l}\boldsymbol{I} \boldsymbol{R}(\boldsymbol{t}): \text { is an insulin infusion rate. } \\
\boldsymbol{y}_{\boldsymbol{i}}: \text { is the measured glucose concentration. } \\
\boldsymbol{B I}: \text { is the steady-state plasma glucose concentration. } \\
\boldsymbol{R I}: \text { is the steady-state infusion rate (that is, for } \boldsymbol{y}_{\boldsymbol{i}}= \\
\boldsymbol{B I} \text { ) } \\
\boldsymbol{Q I}: \text { is the inverse of a static gain. } \\
\boldsymbol{m}: \text { is the slope of the regression line on the last five } \\
\text { measured values of glucose concentration (derivative } \\
\text { control). }\end{array}$ \\
\hline
\end{tabular}




\begin{tabular}{|c|c|c|}
\hline Reference & Equations & Variable description \\
\hline $\begin{array}{l}\text { El-Khatib } \\
\text { et al. [39] }\end{array}$ & $\begin{array}{l}\text { The control algorithm optimizes the multistage quadratic } \\
\text { cost function } \\
\boldsymbol{J}_{G P C}=\sum_{\boldsymbol{k}=\boldsymbol{N}_{\boldsymbol{d}}}^{N_{\boldsymbol{m}}} \boldsymbol{\delta}_{\boldsymbol{k}}\left\|\boldsymbol{C}\left(\boldsymbol{r}_{\boldsymbol{t}-\boldsymbol{k}}-\boldsymbol{y}_{\boldsymbol{t}-\boldsymbol{k}}\right)\right\|^{2}+\sum_{k=0}^{N_{u}} \lambda_{k}\left(\Delta u_{t-k}\right)^{2}\end{array}$ & $\begin{array}{l}\text { GPC: generalized predictive control algorithm to } \\
\text { automatically govern the SC administration of insulin } \\
\text { and glucagon formulations. } \\
u(t) \text { : is input signal to regulate the output BG (blood } \\
\text { glucose) concentration } \\
y(t)] \text { : is output signal online. } \\
\boldsymbol{N}_{\boldsymbol{d}} \text { and } \boldsymbol{N}_{\boldsymbol{m}} \text { : are, respectively, the minimum and } \\
\text { maximum (output) prediction costing horizon limits, } \\
N_{u} \text { : is the control horizon bound, } \\
\boldsymbol{\delta}_{\boldsymbol{k}}: \text { is the weighting on prediction error. } \\
\lambda_{k}: \text { is the weighting on control signals, and the } \\
\text { integrator } \Delta:=1-\mathrm{z}^{-1} \text {, with } \mathrm{z}^{-1} \text { playing the role of a } \\
\text { one-step delay operator. }\end{array}$ \\
\hline $\begin{array}{l}\text { Caleb et } \\
\text { al. [40] }\end{array}$ & $\begin{array}{l}\text { The Glucose-Insulin feedback system: } \\
\qquad \begin{aligned} \frac{d x}{d t}=f_{1}(z)-E\left(\frac{x}{V_{1}}-\frac{y}{V_{2}}\right)-\frac{x}{t_{1}} \\
\frac{d y}{d t}=E\left(\frac{x}{V_{1}}-\frac{y}{V_{2}}\right)-\frac{y}{t_{2}} \\
\frac{d z}{d t}=f_{5}\left(h_{3}\right)+I-f_{2}(z)-f_{3}(z) f_{4}(y) \\
\frac{d h_{1}}{d t}=\frac{3\left(x-h_{1}\right)}{t_{1}} \\
\frac{d h_{2}}{d t}=\frac{3\left(h_{1}-h_{2}\right)}{t_{2}} \\
\frac{d h_{3}}{d t}=\frac{3\left(h_{2}-h_{3}\right)}{t_{3}}\end{aligned}\end{array}$ & 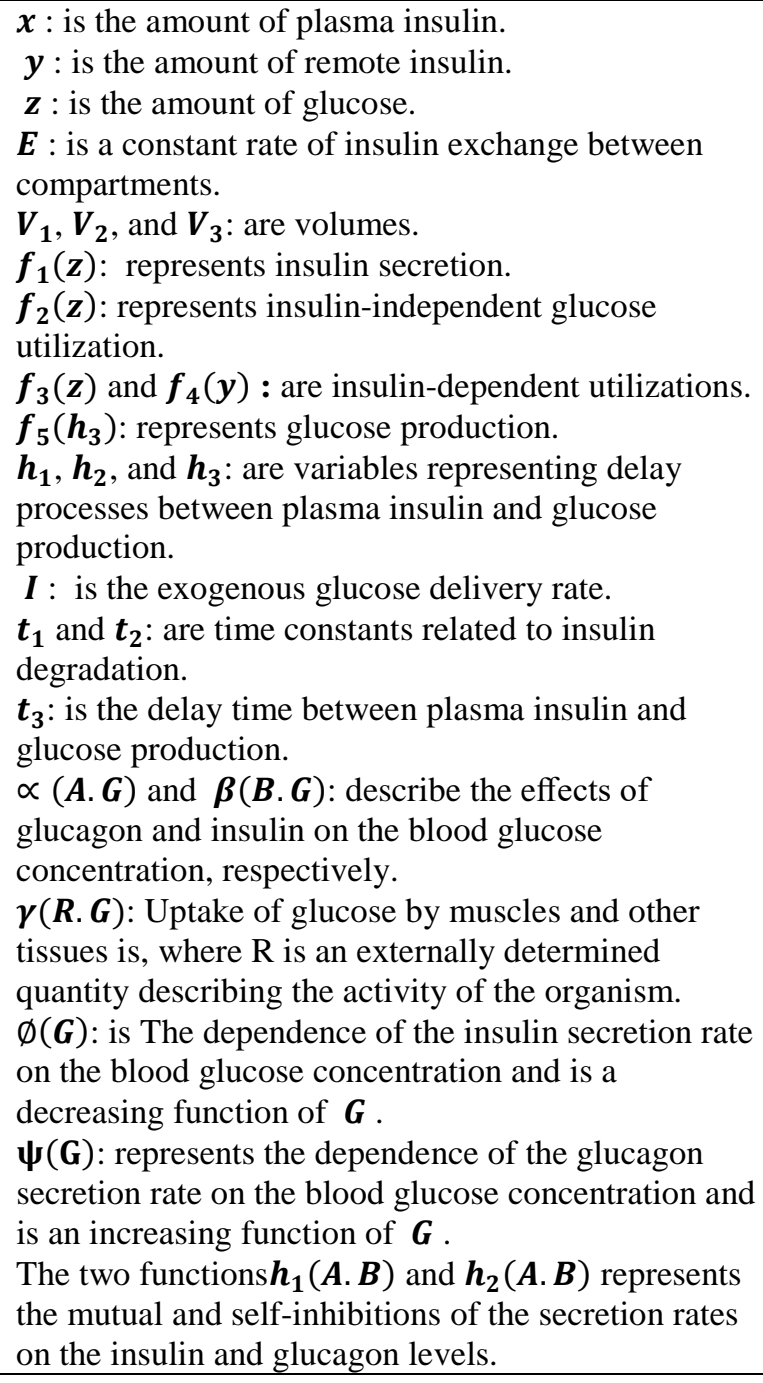 \\
\hline $\begin{array}{l}\text { Minimal } \\
\text { model } \\
\text { (piecewise } \\
\text {-linear) } \\
\text { Dalla Man } \\
\text { et al. [33] }\end{array}$ & $\begin{array}{l}\text { Glucose concentration and Insulin action: } \\
\left\{\begin{array}{cc}\dot{G}(t)=\left[p_{1}+X(t)\right] G(t)+p_{1} G_{b}+\frac{R a(t)}{V} ; \quad & G(0)=G_{b} \\
\dot{X}(t)=-p_{2} X(t)+p_{3}\left[I(t)-I_{b}\right] ; & X(0)=0\end{array}\right.\end{array}$ & $\begin{array}{l}G: \text { is glucose concentration. } \\
X: \text { is insulin action. } \\
I: \text { is insulin plasma concentration. } \\
R a: \text { is the glucose rate of appearance in plasma. } \\
V: \text { is the volume distribution. } \\
\text { suffix " } b \text { ”: denotes basal (pretest). }\end{array}$ \\
\hline
\end{tabular}




\begin{tabular}{|c|c|c|}
\hline Reference & Equations & Variable description \\
\hline & $\begin{array}{l}\text { Piecewise-Linear Model to find } \mathbf{R a}(\mathbf{t}): \\
k_{i-1}+\frac{k_{i}\left\{k_{i-1}\right.}{t_{i}-t_{i-1}} ; \quad \text { per } t_{i-1} \leq t \leq t_{i} . i=1 \cdots 7 \\
R a(t)=0 . \quad \text { otherwise }\end{array}$ & $\begin{array}{l}\text { values, and } p_{1}, p_{2} \text {, and } p_{3} \text { are rate parameters. } \\
\text { Specifically, } p_{1}: \text { is the fractional (i.e., per unit } \\
\text { distribution volume) glucose effectiveness (GE) } \\
\text { measuring glucose ability per se to promote glucose } \\
\text { disposal and inhibit glucose production. } \\
p_{2}: \text { is the rate constant of the remote insulin } \\
\text { compartment from which insulin action is emanated. } \\
p_{3}: \text { is a scale factor governing the amplitude of } \\
\text { insulin action. } \\
\left\{k_{i j}\right\} \text { is the unknown parameter set representing the } \\
\text { values of Ra at the break times. }\end{array}$ \\
\hline $\begin{array}{l}\text { Minimal } \\
\text { model } \\
\text { M.E.Fishe } \\
\mathrm{r} \text { et al. } \\
{[41]}\end{array}$ & $\begin{array}{l}\text { Plasma glucose concentration: } \\
\qquad \begin{array}{r}\dot{G}=-p_{1} G-X\left(G+G_{B}\right)+P(t) \\
G(0)=G_{0}\end{array} \\
\text { Plasma insulin concentration: } \\
\qquad \begin{array}{c}\dot{X}=-p_{2} X+p_{3} I \\
X(0)=X_{0}\end{array} \\
\qquad I(0)=I_{0}\end{array}$ & $\begin{array}{l}G(t) \text { : represent the differences of plasma glucose } \\
\text { concentration. } \\
I(t): \text { represent free plasma insulin concentration. } \\
P(t): \text { is the rates of infusion of exogenous glucose. } \\
u(t): \text { is the rates of infusion of exogenous insulin. } \\
X(t): \text { is proportional to the concentration of insulin } \\
\text { in the remote compartment. } \\
G_{B}: \text { the value of corresponds approximately to the } \\
\text { basal plasma glucose concentration found in normal } \\
\text { individuals. } G: \text { is basal values of plasma glucose } \\
\text { concentration. } \\
I: \text { free plasma insulin concentration. } \\
V: \text { is the insulin distribution volume. } \\
n: \text { is the fractional disappearance rate of insulin. }\end{array}$ \\
\hline $\begin{array}{l}\text { Kinetic } \\
\text { modeling } \\
\text { [42] }\end{array}$ & $\begin{array}{l}\dot{x}=u-b_{3} z+G_{\text {exg }} \\
\dot{u}=-k_{0} u-b_{1} b_{3} y+b_{1} b_{3} z+b_{1}\left(b_{0}-G_{\text {exg }}\right) \\
\dot{z}=-k_{2} z+k_{2} y \\
G=G_{\text {exg }}(t)-G U_{1}(t)+N E G B(t)-G_{\text {ren }}(t) \\
G U_{1}(t)=\sum_{i=0}^{n} b_{3} z\left(t_{i}\right)-b_{3} z(0) \\
\operatorname{NEGB}(t)=\sum_{i=0}^{n} b_{3} u\left(t_{i}\right)-u(0)\end{array}$ & $\begin{array}{l}y: \text { is a circulating concentration of insulin. } \\
x: \text { is a circulating concentration of glucose. } \\
u: \text { is the endogenous glucose balance. } \\
z: \text { peripheral insulin-dependent glucose utilization. } \\
b_{i} \text { and } k_{i}: \text { are six parameters that necessary to } \\
\text { identify all state variables } \\
k_{0}: \text { is a supplementing time constant. } \\
\mathrm{G}_{\text {exg }}(\mathrm{t}): \text { exogenous input of glucose } \\
\mathrm{GU}_{1}(\mathrm{t}) \text { : insulin-controlled peripheral glucose } \\
\text { disappearance. } \\
\mathrm{NEGB}(\mathrm{t}): \text { net endogenous glucose balance } \\
\mathrm{G}_{\text {ren }}(\mathrm{t}): \text { renal glucose excretion. }\end{array}$ \\
\hline
\end{tabular}




\begin{tabular}{|c|c|c|}
\hline Reference & Equations & Variable description \\
\hline $\begin{array}{l}\text { Hyuk } \\
\text { Kang et al. } \\
\text { [2] }\end{array}$ & $\begin{array}{l}\text { Glucose equation: } \\
\quad \frac{d x}{d t}=N H G B\left(x \cdot u_{12} \cdot u_{2}\right)-F_{3}-F_{4}-F_{5}+x_{\text {input }} \\
\text { The net hepatic glucose balance: } \\
N H G B\left(x \cdot u_{12} \cdot u_{2}\right)=F_{1}\left(x \cdot u_{12} \cdot u_{2}\right)-F_{2}\left(x \cdot u_{12}\right) \\
\frac{\text { Insulin equations: }}{\frac{d u_{1 p}}{d t}}=-k_{21} u_{1 p}+k_{12} u_{2 p}+W(x) \\
\qquad \frac{d u_{2 p}}{d t}=k_{21} u_{1 p}-k_{12} u_{2 p}-F_{6}\left(u_{2 p} \cdot x\right) \\
\quad+\frac{d u_{11}}{d t}=-\left(m_{01}+m_{21}+m_{31}\right) u_{11}+m_{12} u_{12}+m_{13} u_{13} \\
\qquad \frac{d u_{12}}{d t}=-\left(m_{02}+m_{12}\right) u_{12}+m_{21} u_{11}+F_{6}\left(u_{2 p} \cdot x\right) \\
\qquad \frac{d u_{13}}{d t}=-m_{13} u_{13}+m_{31} u_{11} \\
\text { Glucagon equation: } \\
\qquad \frac{d u_{2}}{d t}=-h_{02} u_{2}+F_{7}\left(x \cdot u_{13}\right)\end{array}$ & $\begin{array}{l}x: \text { denotes the amount of glucose in the plasma and } \\
\text { extracellular fluids. } \\
u_{1 p}: \text { is the amount of stored insulin in the pancreas. } \\
u_{2 p}: \text { is the amount of promptly releasable insulin in } \\
\text { the pancreas. } \\
u_{11}: \text { is the amount of insulin in the plasma. } \\
u_{12}: \text { is the amount of insulin in the liver. } \\
u_{13}: \text { is the amount of insulin in the interstitial fluids. } \\
u_{2}: \text { is the amount of glucagon in the plasma and } \\
\text { interstitial fluids. } \\
m_{i j}, h_{i j} \text { and } k_{i j}: \text { are appropriate rate constants. } \\
W, F_{6} \text { and } F_{7}: \text { represent the insulin synthesis rate, } \\
\text { insulin secretion rate and glucagon secretion rate, } \\
\text { respectively. } \\
x_{\text {input }} \text { and } u_{\text {input }}: \text { describe the input rates of glucose } \\
\text { and insulin to the plasma, respectively. } \\
\text { Figure } 7\end{array}$ \\
\hline [43] & 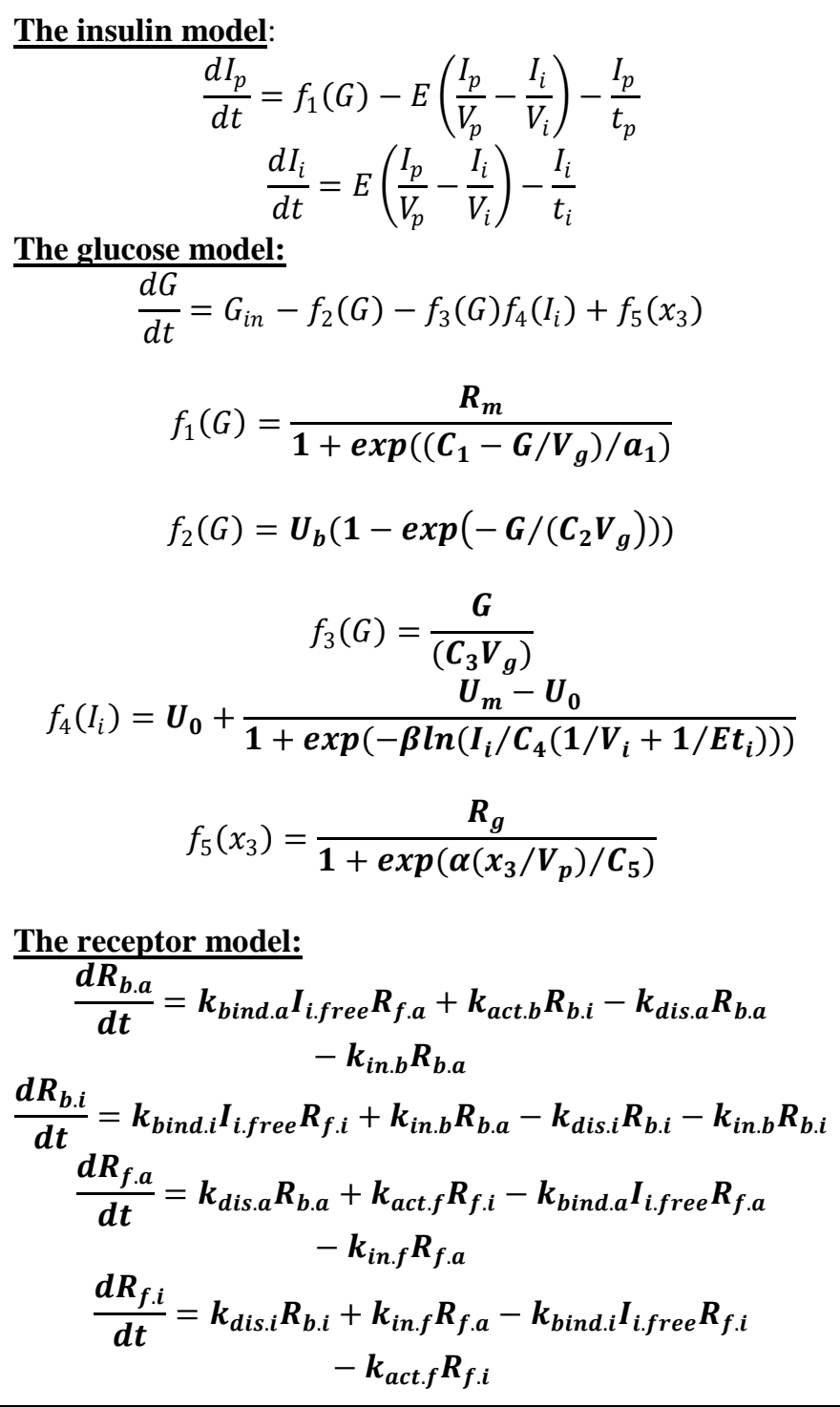 & 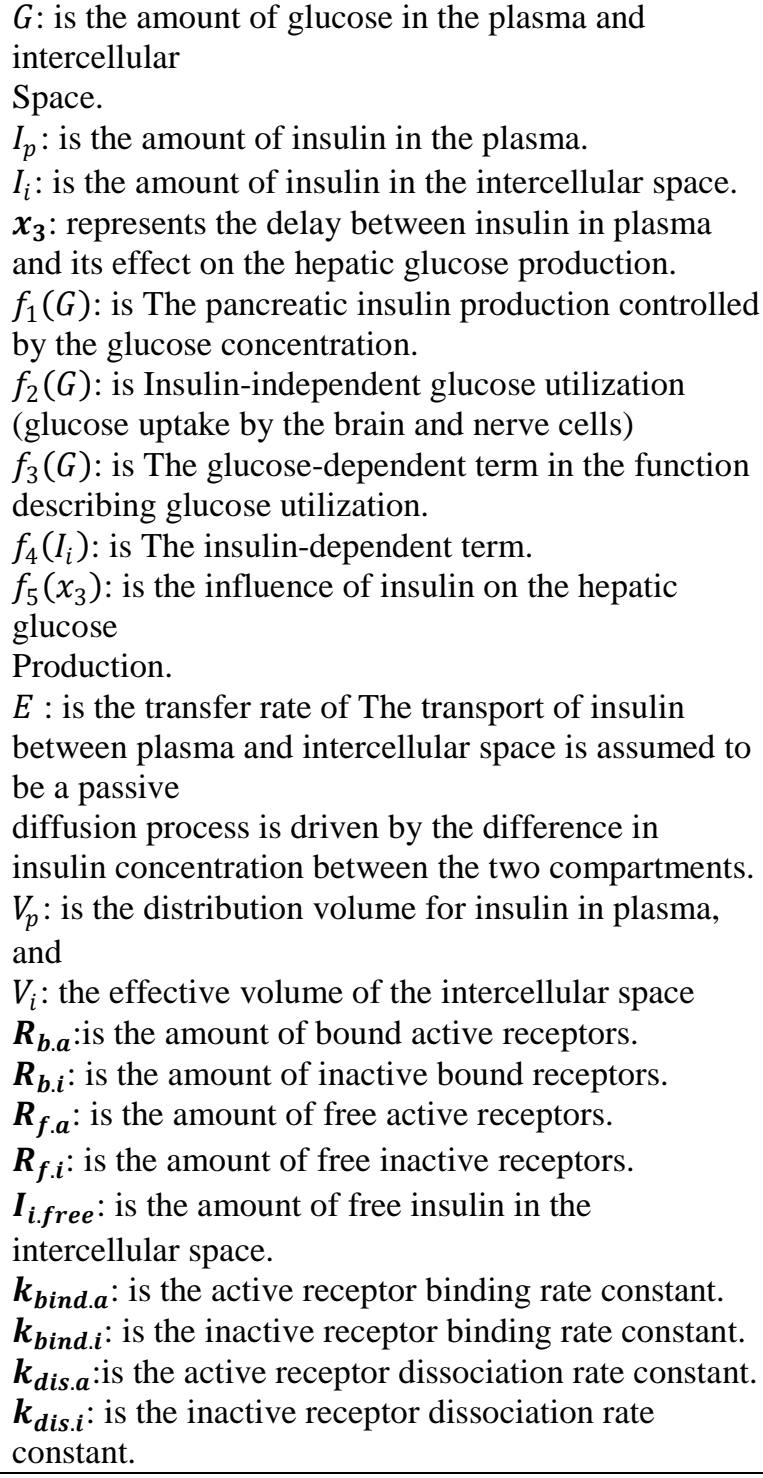 \\
\hline
\end{tabular}




\begin{tabular}{|c|c|c|}
\hline Reference & Equations & Variable description \\
\hline & & $\begin{array}{l}\boldsymbol{k}_{\text {act. }}: \text { is the bound receptor activation rate constant. } \\
\boldsymbol{k}_{\text {act.f }}: \text { is the free receptor activation rate constant. } \\
\boldsymbol{k}_{\text {in.b }}: \text { is the bound receptor inactivation rate constant. } \\
\boldsymbol{k}_{\text {in.f. }}: \text { is the free receptor inactivation rate constant . }\end{array}$ \\
\hline $\begin{array}{l}\text { Dalla Man } \\
\text { et al. [28] }\end{array}$ & 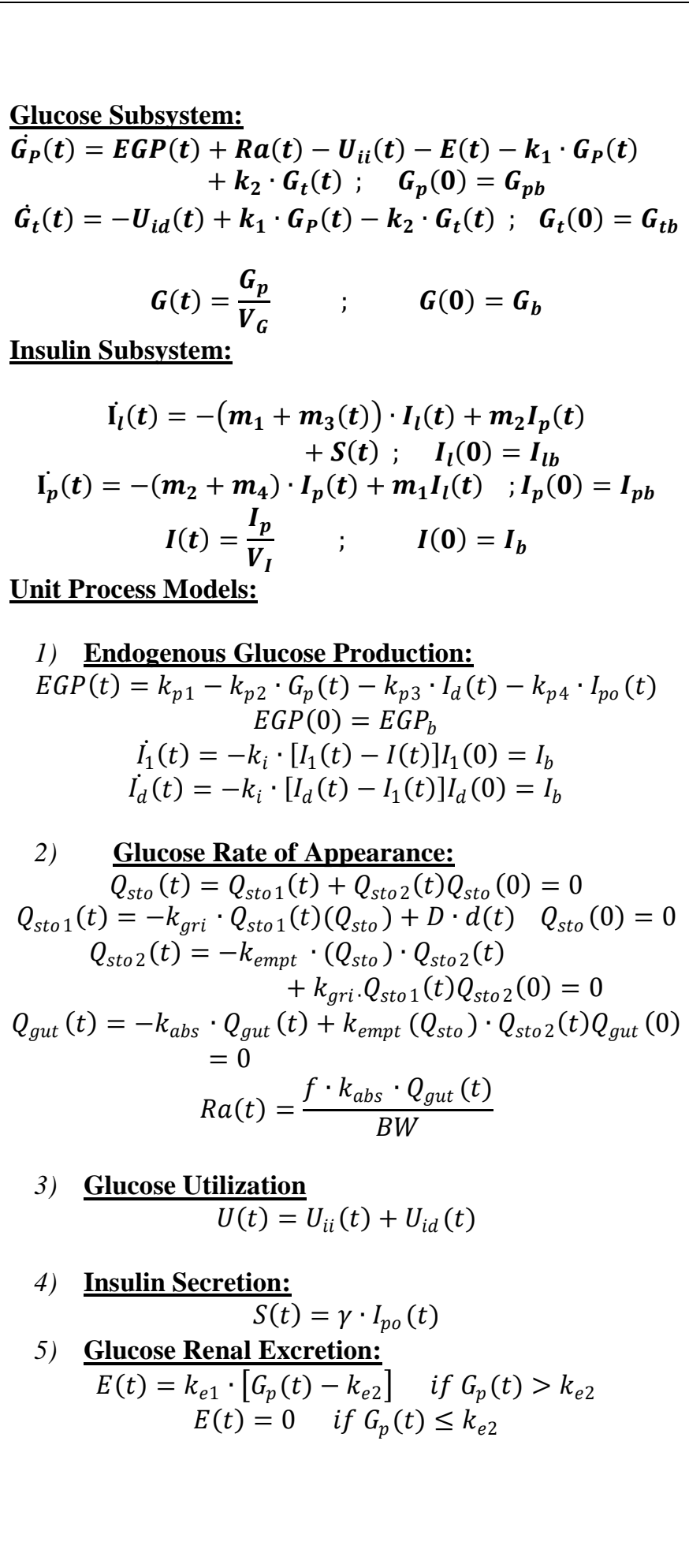 & 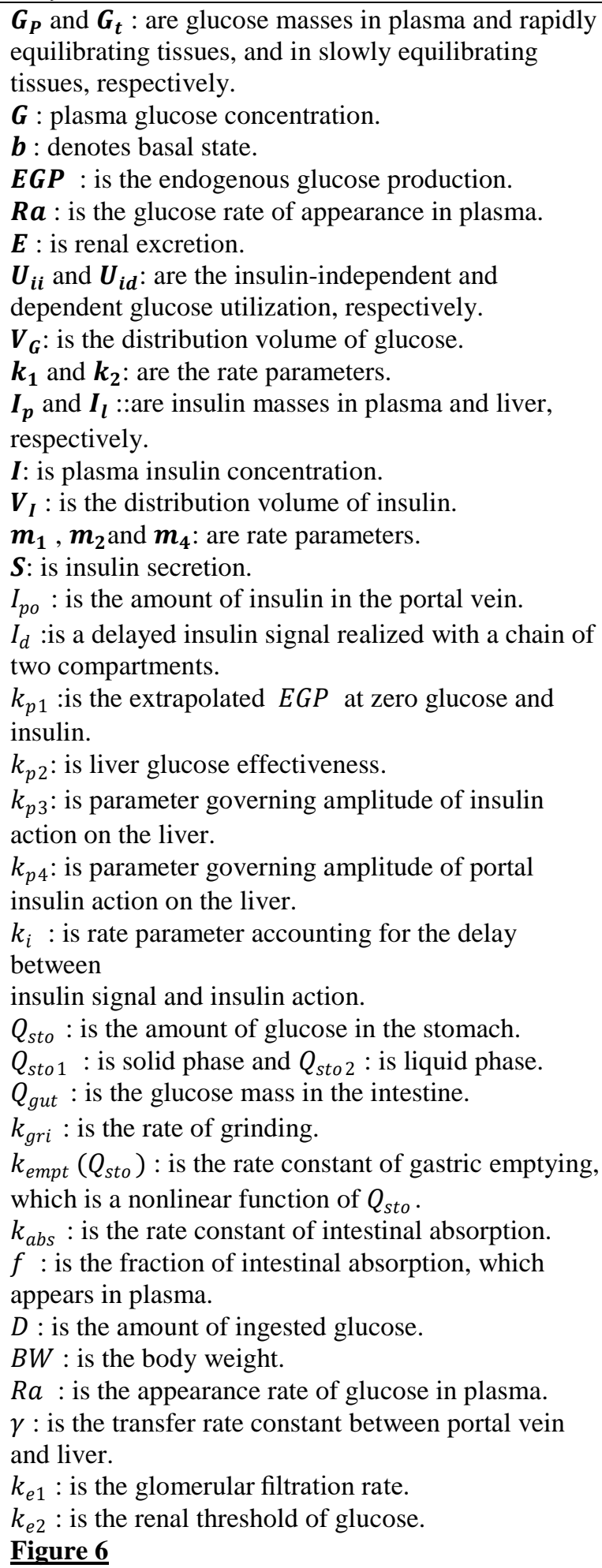 \\
\hline
\end{tabular}




\section{CONCLUSION}

This paper explains the general mechanism of the (glucoseinsulin -glucagon) system. It extracts the main equations from researches whichshow mathematical models in blood glucose regulatory system that have been done among thirteen research which were studied by biochemistry, medical, biophysical, physiological researchers. Much work can be done in the future to improve the blood glucose regulatory system in diabetes. It is known that science has not found the exact mechanism of how this system works, but it is an ongoing challenge that keeps scientists working continually in order to improve their hypotheses as much as possible to help diabetics in the world.

\section{REFERENCE}

[1] D. Meszéna, "Model-based analysis and parameter estimation of a human blood glucose control system model," 2014.

[2] H. Kang, K. Han, and M. Choi, "Mathematical model for glucose regulation in the whole-body system," Islets, vol. 4, no. 2, pp. 84-93, Mar. 2012, doi: 10.4161/isl.19505.

[3] M. Brenner et al., "Estimation of insulin secretion, glucose uptake by tissues, and liver handling of glucose using a mathematical model of glucose-insulin homeostasis in lean and obese mice,” Heliyon, vol. 3, no. 6, p. e00310, Jun. 2017, doi: 10.1016/j.heliyon.2017.e00310.

[4] O. Vahidi, "Dynamic modeling of glucose metabolism for the assessment of type II diabetes mellitus," PhD Thesis, University of British Columbia, 2013.

[5] M. Giugliano, M. Bove, and M. Grattarola, "Insulin release at the molecular level: metabolicelectrophysiological modeling of the pancreatic betacells,” IEEE Trans. Biomed. Eng., vol. 47, no. 5, pp. 611-623, 2000.

[6] N. A. Abbasi and O. B. Akan, "An Information Theoretical Analysis of Human Insulin-Glucose System Toward the Internet of Bio-Nano Things,” IEEE Trans. Nanobioscience, vol. 16, no. 8, pp. 783-791, 2017.

[7] P. Jauslin-Stetina, "Mechanism-Based Modeling of the Glucose-Insulin Regulation during Clinical Provocation Experiments," PhD Thesis, Acta Universitatis Upsaliensis, 2008.

[8] U. Jamaludin, "Developing and validating a new comprehensive glucose-insulin pharmacokinetics and pharmacodynamics model," 2013.

[9] C.-W. Lin, "Modeling glucose-insulin kinetics and development of type 2 diabetes in offspring of diabetic parents,” PhD, University of Iowa, Iowa City, Iowa, USA, 2011.

[10] R. R. Whitesell, D. M. Regen, and N. A. Abumrad, "Evidence for functionally distinct glucose transporters in basal and insulin-stimulated adipocytes," Biochemistry, vol. 28, no. 17, pp. 6937-6943, Aug. 1989, doi: 10.1021/bi00443a024.

[11] I. Kojima, J. Medina, and Y. Nakagawa, "Role of the glucose-sensing receptor in insulin secretion,” Diabetes Obes. Metab., vol. 19, pp. 54-62, 2017.

[12] I. Quesada, E. Tudurí, C. Ripoll, and Á. Nadal, "Physiology of the pancreatic $\alpha$-cell and glucagon secretion: role in glucose homeostasis and diabetes,” $J$.
Endocrinol., vol. 199, no. 1, pp. 5-19, Oct. 2008, doi: 10.1677/JOE-08-0290.

[13] P. G. Jacobs et al., "Development of a fully automated closed loop artificial pancreas control system with dual pump delivery of insulin and glucagon,” in 2011 Annual International Conference of the IEEE Engineering in Medicine and Biology Society, 2011, pp. 397-400.

[14] G. M. Grodsky, “A threshold distribution hypothesis for packet storage of insulin and its mathematical modeling,” J. Clin. Invest., vol. 51, no. 8, pp. 20472059, 1972.

[15] M. Ohara-Imaizumi, C. Nishiwaki, T. Kikuta, S. Nagai, Y. Nakamichi, and S. Nagamatsu, "TIRF imaging of docking and fusion of single insulin granule motion in primary rat pancreatic $\beta$-cells: different behaviour of granule motion between normal and Goto-Kakizaki diabetic rat $\beta$-cells,” Biochem. J., vol. 381, no. 1, pp. 1318, 2004.

[16] S. Nagamatsu, "TIRF microscopy analysis of the mechanism of insulin exocytosis," Endocr. J., pp. 0606260021-0606260021, 2006.

[17] M. Ohara-Imaizumi et al., "Imaging analysis reveals mechanistic differences between first-and second-phase insulin exocytosis," J. Cell Biol., vol. 177, no. 4, pp. 695-705, 2007.

[18] R. V. Overgaard, K. Jelic, M. Karlsson, J. E. Henriksen, and H. Madsen, "Mathematical beta cell model for insulin secretion following IVGTT and OGTT," Ann. Biomed. Eng., vol. 34, no. 8, pp. 1343-1354, 2006.

[19] G. Toffolo, M. Campioni, R. Basu, R. A. Rizza, and C. Cobelli, "A minimal model of insulin secretion and kinetics to assess hepatic insulin extraction," Am. J. Physiol.-Endocrinol. Metab., vol. 290, no. 1, pp. E169E176, 2006.

[20] A. De Gaetano and O. Arino, "Mathematical modelling of the intravenous glucose tolerance test," J. Math. Biol., vol. 40, no. 2, pp. 136-168, 2000.

[21] G. Toffolo, R. N. Bergman, D. T. Finegood, C. R. Bowden, and C. Cobelli, "Quantitative estimation of beta cell sensitivity to glucose in the intact organism: a minimal model of insulin kinetics in the dog," Diabetes, vol. 29, no. 12, pp. 979-990, 1980.

[22] N. Gupta, R. P. Hoffman, and P. Veng-Pedersen, "Pharmacokinetic/pharmacodynamic differentiation of pancreatic responsiveness in obese and lean children," Biopharm. Drug Dispos., vol. 26, no. 7, pp. 287-294, 2005.

[23] "Scheme of mechanism of glucose-induced insulin secretion (4) | Download Scientific Diagram.” [Online]. Available: https://www.researchgate.net/figure/Schemeof-mechanism-of-glucose-induced-insulin-secretion4_fig4_319555151. [Accessed: 07-Aug-2019].

[24] H. Kristinsson, "Effects of Free Fatty Acids on Insulin and Glucagon Secretion:-with special emphasis on the role of Free fatty acid receptor 1,” PhD Thesis, Acta Universitatis Upsaliensis, 2017.

[25] "Glucose Regulation.” [Online]. Available: https://www.austincc.edu/apreview/EmphasisItems/Gluc ose_regulation.html. [Accessed: 02-Aug-2019].

[26] E. Gylfe, "Glucose Control of Glucagon Secretion: There Is More to It Than KATP Channels,” Diabetes, vol. 62, no. 5, pp. 1391-1393, May 2013, doi: 10.2337/db13-0193. 
[27] E. Ackerman, L. C. Gatewood, J. W. Rosevear, and G. D. Molnar, "Model studies of blood-glucose regulation," Bull. Math. Biophys., vol. 27, no. 1, pp. 21-37, 1965.

[28] C. Dalla Man, R. A. Rizza, and C. Cobelli, "Meal simulation model of the glucose-insulin system," IEEE Trans. Biomed. Eng., vol. 54, no. 10, pp. 1740-1749, 2007.

[29] C. Cobelli and A. Mari, "Validation of mathematical models of complex endocrine-metabolic systems. A case study on a model of glucose regulation,” Med. Biol. Eng. Comput., vol. 21, no. 4, pp. 390-399, 1983.

[30] M. E. Fisher and K. L. Teo, “Optimal insulin infusion resulting from a mathematical model of blood glucose dynamics,” IEEE Trans. Biomed. Eng., vol. 36, no. 4, pp. 479-486, 1989.

[31] R. N. Bergman, "Minimal model: perspective from 2005,” Horm. Res. Paediatr., vol. 64, no. Suppl. 3, pp. 8-15, 2005.

[32] R. N. Bergman, "Toward physiological understanding of glucose tolerance: minimal-model approach,” Diabetes, vol. 38, no. 12, pp. 1512-1527, 1989.

[33] C. Della Man, A. Caumo, and C. Cobelli, "The oral glucose minimal model: estimation of insulin sensitivity from a meal test,” IEEE Trans. Biomed. Eng., vol. 49, no. 5, pp. 419-429, 2002.

[34] R. N. Bergman, R. Prager, A. Volund, and J. M. Olefsky, "Equivalence of the insulin sensitivity index in man derived by the minimal model method and the euglycemic glucose clamp.,” J. Clin. Invest., vol. 79, no. 3, pp. 790-800, 1987.

[35] S. Welch, S. S. P. Gebhart, R. N. Bergman, and L. S. Phillips, "Minimal model analysis of intravenous glucose tolerance test-derived insulin sensitivity in diabetic subjects,” J. Clin. Endocrinol. Metab., vol. 71, no. 6, pp. 1508-1518, 1990.

[36] G. M. Steil, A. Volund, S. E. Kahn, and R. N. Bergman, "Reduced sample number for calculation of insulin sensitivity and glucose effectiveness from the minimal model: suitability for use in population studies," Diabetes, vol. 42, no. 2, pp. 250-256, 1993.

[37] K. Zarkogianni, A. Vazeou, S. G. Mougiakakou, A. Prountzou, and K. S. Nikita, "An insulin infusion advisory system based on autotuning nonlinear modelpredictive control," IEEE Trans. Biomed. Eng., vol. 58, no. 9, pp. 2467-2477, 2011.

[38] C. Cobelli and A. Ruggeri, "Evaluation of portal/peripheral route and of algorithms for insulin delivery in the closed-loop control of glucose in diabetes-A modeling study," IEEE Trans. Biomed. Eng., no. 2, pp. 93-103, 1983.

[39] F. H. El-Khatib, J. Jiang, and E. R. Damiano, “Adaptive closed-loop control provides blood-glucose regulation using dual subcutaneous insulin and glucagon infusion in diabetic swine,” J. Diabetes Sci. Technol., vol. 1, no. 2, pp. 181-192, 2007.

[40] C. L. Adams and D. G. Lasseigne, "An extensible mathematical model of glucose metabolism. Part I: the basic glucose-insulin-glucagon model, basal conditions and basic dynamics," Lett. Biomath., vol. 5, no. 1, pp. 70-90, Dec. 2018, doi: 10.1080/23737867.2018.1429332.

[41] M. E. Fisher, "A semiclosed-loop algorithm for the control of blood glucose levels in diabetics," IEEE Trans. Biomed. Eng., vol. 38, no. 1, pp. 57-61, 1991.

[42] E. Salzsieder, G. Albrecht, U. Fischer, and E.-J. Freyse, "Kinetic modeling of the glucoregulatory system to improve insulin therapy,” IEEE Trans. Biomed. Eng., no. 10, pp. 846-855, 1985.

[43] I. M. Tolić, E. Mosekilde, and J. Sturis, "Modeling the insulin-glucose feedback system: the significance of pulsatile insulin secretion,” J. Theor. Biol., vol. 207, no. 3, pp. 361-375, 2000. 